\title{
A noção de gestão democrática e sua apropriação local: um estudo sobre a legislação de municípios gaúchos
}

\section{The notion of democratic management and its local appropriation: a study on the legislation of municipalities of $R S$}

La noción de gestión democrática y su apropiación local: un estudio sobre la legislación de los municipios gaúchos

ROSIMAR SERENA SIQUEIRA ESQUINSANI

Orcid iD: http://orcid.org/ 0000-0002-6918-2899 Universidade de Passo Fundo - Rio Grande do Sul.

JARBAS DAMETTO

Orcid iD: http://orcid.org/0000-0003-2053-984X Universidade de Passo Fundo - Rio Grande do Sul. MUNIR JOSÉ LAUER

Orcid iD: 0000-0003-2561-786X

Rede estadual de ensino - Pontão - Rio Grande do Sul.

\begin{abstract}
Resumo: A Constituição 1988 e a LDB 9.394/1996, embora lembrem o princípio da gestão democrática, não detalham seu significado, extensão e mecanismos para a sua implementação no ensino público. Através da abordagem dos 497 planos municipais de educação do Rio Grande do Sul, propõe-se a discussão dos principais critérios apresentados como indicadores de gestão democrática nas legislações municipais: desempenho; eleição de diretores; instituição e manutenção de colegiados. Desenham-se, assim, indicadores que expressam a dimensão normativa da gestão democrática nos municípios gaúchos, instituídos frente à polissemia do significante "democracia" e da imprecisão da legislação nacional.
\end{abstract}

Palavras-chave: Planos municipais de educação; Gestão democrática; Legislação local.

Abstract: The 1988 Constitution and the LDB 9.394/1996, while indicating the principle of Democratic Management, do not specify in detail its meaning, extent and mechanisms for its implementation in public education. Through the approach of the 497 Municipal Education Plans of Rio Grande do Sul, it is proposed to discuss the main criteria presented as indicators of democratic management in municipal legislations: performance; election of directors; institution and maintenance of collegiate. Thus, indicators express the normative dimension of Democratic Management in the cities of Rio Grande do Sul, instituted in the face of the polysemy of significant 'democracy' and the imprecision of national legislation.

Keywords: Municipal Education Plans. Democratic Management. Local Legislation. 
Resumen: La Constitución de 1988 y la LDB 9.394 / 1996, aunque indiquen el principio de Gestión Democrática, no especifican en detalle su significado, alcance y mecanismos para su implementación en la educación pública. A través del enfoque de los 497 Planes de Educación Municipal de Rio Grande do Sul, se propone discutir los principales criterios presentados como indicadores de gestión democrática en las legislaciones municipales: desempeño; elección de directores; institución y mantenimiento de colegiado. Así, se expresan indicadores que expresan la dimensión normativa de la Gestión Democrática en las ciudades de Rio Grande do Sul, instituida frente a la polisemia de la 'democracia' significativa y la imprecisión de la legislación nacional.

Palabras clave: Planes de educación municipal. Gestión democrática. Legislación local.

\section{INTRODUÇÃO}

O presente trabalho discute o termo "gestão democrática" no registro dos planos municipais de educação (PMEs) do Rio Grande do Sul, particularmente em razão dos principais critérios apresentados como indicadores de gestão democrática nas legislações municipais: desempenho; eleição de diretores; instituição e manutenção de colegiados. Para tal discussão, analisa as leis que compõem os planos de educação dos 497 municípios sul-rio-grandenses. Como comparativo, buscou-se também compreender o que o Plano Nacional de Educação (PNE - inciso IV, artigo 9 ${ }^{\circ}$, meta 19 e suas estratégias - lei $\mathrm{n}^{\circ}$ 13.005/14) e o Plano Estadual de Educação (PEE - inciso IV, meta 19 e suas estratégias - lei no 14.705/15) mencionam sobre o termo "gestão democrática", pois, conjunturalmente, estes planos serviram de base para todo o processo de construção/elaboração dos planos municipais.

Ainda que a ideia de uma gestão educacional e escolar complementada pelo adjetivo "democrática" seja hoje quase uma unanimidade discursiva, sendo mesmo compreendida como "uma forma de exercitar a democracia participativa, podendo contribuir para a própria democratização da sociedade" (GRACINDO, 2007, p. 39), há que se construir e solidificar os consensos práticos acerca do termo, pois:

Embora existam na Constituição Federal mais recente e na Lei de Diretrizes e Bases da Educação Nacional referências e princípios da gestão democrática e da qualidade do ensino público, essas disposições legais esbarram [...] na insuficiência em descrever e definir com maior precisão mecanismos que garantam ações administrativas educacionais efetivamente mais democráticas. (PASSADOR; SALVETTI, 2013, p. 480).

Para cumprir seu objetivo, a pesquisa que deu origem ao texto em tela foi realizada prioritariamente em base documental e bibliográfica (revisão temática), pautada por uma metodologia analítico-reconstrutiva materializada através da 
descrição, categorização, exame e reconstrução de argumentos, apresentando potenciais subsídios ao debate sobre o princípio da gestão democrática do ensino público, especialmente as leituras das legislações locais acerca do tema. Os textos dos PMEs sul-rio-grandenses compuseram o corpus documental e foram examinados a partir do procedimento da análise de conteúdo, compreendida como "um conjunto de técnicas de análise das comunicações, que utiliza procedimentos sistemáticos e objetivos de descrição do conteúdo das mensagens" (BARDIN, 2007, p. 38), utilizando-se a técnica da análise temática, na qual o "tema é a unidade de significação que se liberta naturalmente de um texto analisado, segundo critérios relativos à teoria que serve de guia à leitura." (p.105).

Estruturalmente, para dar conta da discussão do termo "gestão democrática", seu significado, sua extensão e os mecanismos para a sua implementação no ensino público, são elaborados três movimentos: no primeiro são apresentados os elementos do PNE e do PEE, suas similitudes e diferenças quanto ao termo e possível materialização da gestão democrática. Posteriormente, são expostas as noções de gestão democrática em parte dos 497 planos municipais sul-rio-grandenses. Em um terceiro movimento, são levantadas discussões teóricas sobre os achados da pesquisa, mormente os principais critérios apresentados como indicadores de gestão democrática nas legislações municipais: desempenho; eleição de diretores; instituição e manutenção de colegiados.

\section{A TERMINOLOGIA “GESTÃO DEMOCRÁTICA” NA LEGISLAÇÃO}

A expressão "gestão democrática" do ensino público figura pela primeira vez em um documento legal com envergadura nacional, na Constituição Federal de 1988, no artigo 206, inciso VI, sendo repetido, posteriormente, em diversos outros documentos jurídico-normativos, notadamente, na Lei de Diretrizes e Bases da Educação Nacional, no 9.394/96, no artigo 3º inciso VIII e no artigo 14 da mesma lei. O termo ainda figurou em três momentos do PNE anterior, lei $\mathrm{n}^{\circ}$ 10.172, de 9 de janeiro de 2001.

A emenda constitucional no 59/2009 (EC no 59/2009) mudou a condição do PNE, que passou de uma disposição transitória da Lei de Diretrizes e Bases da Educação Nacional ( $n^{\circ}$ 9.394/1996) para uma exigência constitucional com periodicidade decenal. 
O atual PNE (lei no 13.005/2014) exibe o termo em dois artigos: artigo $2^{\circ}$, inciso VI, e artigo $9^{\circ}$, que estabelece prazos e providências por parte de cada ente federado quanto à regulamentação de leis específicas para o tratamento do tema. Em sequência - no anexo da lei - exibe a meta 19, que é toda afeta à gestão democrática:

Meta 19: assegurar condições, no prazo de 2 (dois) anos, para a efetivação da gestão democrática da educação, associada a critérios técnicos de mérito e desempenho e à consulta pública à comunidade escolar, no âmbito das escolas públicas, prevendo recursos e apoio técnico da União para tanto. (BRASIL, 2014).

As oito estratégias subsequentes à meta trazem quatro focos para consecução da "efetivação da gestão democrática da educação": o fortalecimento de colegiados, nas estratégias 19.2,19.3, 19.4 e 19.5; a participação, designadamente na estratégia 19.6; a autonomia pedagógica, administrativa e de gestão financeira, na estratégia 19.7; e, por fim, o zelo para com a especificidade da gestão escolar (formação e/ou eleição de diretores), nas estratégias 19.1 e 19.8.

Há, portanto, quatro definições objetivas do que os marcos normativos infraconstitucionais designam por "pilares" de uma gestão democrática: a participação; a autonomia; os colegiados e a gestão escolar, notadamente na figura do gestor (diretor) escolar. Porém, tais pilares não são, exatamente, consensos, visto que...

[...] não existe um modelo de democracia de validez universal, sendo necessária a institucionalização de práticas democráticas nas diversas formas de relações sociais, que construiriam, assim, uma sociedade mais inclusiva. [...] ideia da indecibilidade e da incompletude da democracia, que é uma construção contínua e contingente que se dá através de práticas articulatórias nos diferentes espaços sociais. (MARQUES, 2012, p. 1178).

Já o PEE, em meta correlata e também numerada como 19, adiciona alguns elementos aos esforços de materialização da gestão democrática:

Assegurar condições, sob responsabilidade dos sistemas de ensino, durante a vigência do Plano, para a efetivação da gestão democrática da educação pública e do regime de colaboração, através do fortalecimento de conselhos de participação e controle social, e da gestão democrática escolar, considerando três pilares, no âmbito das escolas públicas: conselhos escolares, descentralização de recursos e progressivos mecanismos de autonomia financeira e administrativa e provimento democrático da função de gestor, prevendo recursos e apoio técnico da União, bem como recursos próprios da esfera estadual e municipal; para a manutenção dos respectivos conselhos de educação. (RIO GRANDE DO SUL, 2015). 
Assim, a Meta 19 do PEE sugere quanto à gestão: a) ênfase em três pilares, identificados como: conselhos escolares, descentralização de recursos e progressivos mecanismos de autonomia financeira e administrativa, e provimento democrático da função de gestor; b) processo de eleição envolvendo toda a comunidade escolar com proporção igualitária, isto é, $50 \%$ do segmento de pais e educandos, mais $50 \%$ do segmento de professores e funcionários; c) defesa da gestão da educação pública por meio e métodos não baseados na introdução da lógica dos negócios e de mercado nos assuntos educacionais; d) garantia as formas específicas de gestão (respeitando as necessidades e os costumes de grupos culturais e sociais) (RIO GRANDE DO SUL, 2015).

Em síntese, o PNE indica uma gestão com fortes traços em defesa da meritocracia como marca central da gestão, em que o mérito e o desempenho fazem parte do mesmo contexto, tendo a consulta à comunidade escolar como um fator associativo, secundário e sem detalhamento quanto ao modo de sua efetivação. A forma de provimento de gestores nesse ideário, isto é, o provimento misto e a indicação de prova nacional específica, caracterizam tal concepção de gestão. Embutido nesse contexto, presume-se uma aproximação de conceitos da meritocracia com a administração empresarial.

O PEE, no entanto, aparenta contrapor-se à gestão empresarial. Nesse contexto, a gestão é compreendida como de caráter participativo, em um primeiro olhar, envolvendo a comunidade escolar, perceptível pela forma sugerida para o provimento dos gestores: por meio de eleição direta, pela comunidade escolar. O PEE, não menciona, em nenhum momento, processos de escolha de gestores fora de um pleito eleitoral, nem capacitação técnica para isso.

Os PMEs foram elaborados tendo como suporte preferencial (por ter sido formulado em momento anterior) o PNE e, subsidiariamente, pelo PEE. Assim, os PMEs parecem dividir opiniões e prescrições no tocante ao termo e à materialidade da gestão democrática do ensino público. Somado a isso, os próprios municípios possuem suas peculiaridades e contextos. Nesse complexo emaranhado de visões, é que se fundaram os planos municipais.

Quanto à descrição da gestão na forma da lei, os planos municipais, na maioria dos casos (396 municípios), apresentam emparelhamento (quando não apenas cópia) com o proposto pelo PNE; e em menor número (59), há o emparelhamento com o que o PEE descreve como "gestão democrática". Apenas 42 PMEs apresentam conteúdos diferenciados no que tange à gestão democrática do ensino público.

É pertinente sublinhar que o PNE foi formulado anteriormente ao PEE, e este foi elaborado no mesmo período em que muitos PMEs estavam nesse mesmo processo. 
Vale lembrar que a trajetória do PNE se inicia com o projeto de lei $\mathrm{n}^{\circ}$ 8.035/2010, que tramitou na Câmara dos Deputados até o ano de 2012, quando foi remetido ao Senado Federal, recebendo nova numeração: Projeto de Lei da Câmara no 103/2012, sendo sancionado em 25 de junho de 2014, deflagrando os movimentos de elaboração dos planos estaduais e municipais de educação em todo território nacional. Já o PEE do Rio Grande do Sul foi sancionado em 25 de junho de 2015, em data similar à boa parte dos PMEs. Portanto, parece lícito supor que muitos municípios tiveram apenas o PNE como apoio de conteúdo.

\section{A NOÇÃO DE GESTÃO DEMOCRÁTICA NOS PLANOS MUNICIPAIS DE EDUCAÇÃO DO RIO GRANDE DO SUL}

Em tese, o PME seria o instrumento jurídico-normativo responsável por definir a concepção e possibilitar a efetivação do projeto municipal de educação, ultrapassando rotinas, ações segmentadas e improvisações. Justo por este viés, seria lícito supor que os PMEs teriam o condão do detalhamento, do olhar regionalizado, da especificidade.

Durante a análise dos PMEs sul-rio-grandenses, percebeu-se que 150 municípios não fazem menção alguma à gestão democrática na lei que cria o referido plano. Isto é, no corpo da lei não consta nada, nenhum artigo ou referência ao princípio de gestão democrática. Entretanto, esses mesmos municípios que não mencionam a gestão democrática, o fazem no espaço destinado ao anexo da lei (na configuração de meta e estratégias).

Entre os 497 planos analisados, detectou-se em 80 PMEs (16\% do total de legislações locais investigadas) a intencionalidade explícita para organização de uma lei própria para a gestão democrática, como indicado nos excertos ilustrativos em sequência: "Criar a lei municipal de gestão democrática do Sistema Municipal de Ensino, no decorrer da vigência deste PME a fim de promover a finalidade e princípios da gestão democrática" (PME 21); "Instituir, via criação da lei, a gestão democrática municipal, a regulamentação da escolha da direção das escolas [...]" (PME 448); "criar, implantar, e implementar a lei de gestão democrática nas escolas públicas, sob a responsabilidade e suporte técnico da SME e UNDIMERS [...]” (PME 121). Nos demais casos, isto é, nos 417 municípios restantes, percebe-se na redação da lei, uma aproximação com a redação do PNE, com um vínculo ao que é proposto em âmbito nacional pelo artigo $9^{\circ}$ do PNE, e não municipal, num sentido "genérico".

No que tange ao tema "eleição de diretores", um total de 91 municípios $(18,3 \%)$ indicam nos seus planos municipais, a eleição direta de gestores pela comunidade escolar, sendo que em 29 municípios esta é a única forma de 
provimento prevista. Nos demais 62 municípios, a eleição é complementada por indicações (listas tríplices), como no caso do PME 96, que antecipa: "promover consulta prévia da comunidade escolar, para a escolha de direção das escolas municipais, de modo a serem indicados 03 nomes ao executivo para que este faça a indicação de forma participativa, assegurando a nomeação do cargo de direção para 01 dos 03 nomes indicados", ou ainda critérios técnicos, como a participação em cursos para gestores ou a previsão de uma determinada formação em nível superior, como no exemplo do PME 108, que busca: "garantir que o candidato a diretor, bem como seu vice, tenham cumprido, no mínimo, 5 anos efetivos de sala de aula, no município, e tenham formação mínima de graduação. O candidato a diretor poderá escolher seus cargos de confiança, supervisores e orientadores da rede municipal."

Basicamente em relação a explicitações da noção e a materialização da gestão democrática, os 497 PMEs sul-rio-grandenses não distam muito dos registros do PNE e/ou do PEE. Poucas são as inovações, os conteúdos diversos, as vinculações com a expectativa e a realidade locais ou as "ousadias". Há, contudo, 42 municípios que, em vários momentos da redação, permitem-se ser mais descritivos, peculiares ou diretos que o PNE e/ou o PEE, permitindo a inferência de noções e práticas de gestão democrática do ensino público que vão além do já constatado nos planos nacional e estadual e, possivelmente, atendem a demandas e especificidades locais.

Esses 42 municípios podem ser descritos a partir de seus habitantes em: a capital, Porto Alegre, com mais de 1.500 .000 habitantes; dois municípios com mais de 200 mil habitantes; três municípios entre 100 mil e 200 mil habitantes; onze municípios entre 20 mil e 100 mil habitantes; seis municípios entre 10 mil e 20 mil habitantes; e dezenove municípios com menos de 10 mil habitantes.

Na sequência, abordamos os registros contidos nesses 42 PMEs $(8,4 \%$ do total de documentos examinados) que apresentam inovações em relação ao PNE ou PEE, a partir de seis categorias: 1) compreensões sobre o conceito de gestão; 2) apresentação de novos mecanismos para a gestão democrática; 3) previsão de financiamento e controle específico para a gestão; 4) ações tópicas vinculadas à gestão; 5) ações relacionadas ao processo eleitoral/provimento de diretores/ gestores de escolas públicas; 6) previsão de ações específicas para a capacitação/ formação de recursos humanos voltados à gestão.

No que diz respeito à primeira categoria, ou às compreensões sobre o conceito de gestão, parece haver o emparelhamento entre gestão x participação e representatividade social. Nessa categoria, estão excertos, como a necessidade de o PME “ampliar canais de diálogo com a comunidade escolar e outros contextos 
com vista a garantir a gestão escolar democrática e participativa, fortalecendo os conselhos escolares e o intercâmbio de práticas, garantindo a cidade como cenário educativo." (PME 52).

De igual forma, compreende-se que cabe ao plano municipal formalizar a participação, instigando sua prática social e prevendo "incluir nos currículos conteúdos sobre a importância da participação, promovendo a cidadania e a politização dos estudantes, incentivando a organização dos grêmios estudantis nas escolas." (PME, 149).

Outro excerto relevante traz à baila a noção complementar de gestão democrática: a sua condição histórica, que exige esforço e constante monitoria para que seja definida, formalizada e aplicada. Para tanto, é necessário "revisar sistematicamente a legislação municipal que possibilita o exercício da gestão democrática, definindo, em cada estabelecimento de ensino, normas de gestão democrática do ensino público, com a participação da comunidade escolar.” (PME 253). Tal empenho corrobora com a compreensão de que a gestão democrática é um processo:

[...] de aprendizado e de luta política que não se circunscreve aos limites da prática educativa, mas vislumbra, nas especificidades dessa prática social e de sua relativa autonomia, a possibilidade de criação de canais de efetiva participação e de aprendizado do "jogo" democrático e, consequentemente, do repensar das estruturas de poder autoritário que permeiam as relações sociais e, no seio dessas, as práticas educativas. (DOURADO, 2013, p. 97-98).

Outra concepção possível, advinda dos excertos dos PMEs em foco, diz respeito à ampliação de fóruns decisórios como princípio da gestão democrática. Os três excertos a seguir dão ideia da plausibilidade da associação entre a ampliação de espaços de participação e a gestão democrática:

Garantir representação paritária (movimentos sociais e governo) nas discussões decisórias de políticas públicas educacionais do município, reconhecendo a pluralidade de saberes de modo a refletir a diversidade dos agentes e sujeitos políticos do campo educacional. (PME 307).

Garantir o direito à gestão democrática, de modo a promover a participação social ampla na gestão escolar, respeitando as necessidades e os costumes de grupos culturais e sociais específicos - membros de populações tradicionais, como indígenas e quilombolas - e o processo educativo desenvolvido com as pessoas privadas de sua liberdade e a população em situação de rua. (PME 01). 
Garantir o direito às formas alternativas de gestão, de modo a promover a participação social ampla na gestão democrática escolar, respeitando as necessidades e os costumes de grupos culturais e sociais - tais como cidadãos do campo e membros de populações tradicionais quilombolas e itinerantes - e o processo educativo desenvolvido junto às pessoas privadas de sua liberdade. (PME 172).

O que está em discussão nos trechos citados é a garantia da participação como indicador de gestão; percebe-se o caráter ampliado da participação, uma vez que o legislador faz questão de nominar sujeitos sociais, lembrando a intenção de abrangência e inclusão.

Há, por fim, excertos que mostram uma compreensão suficientemente sintética acerca da noção de gestão democrática, vinculada a princípios fundamentais, descritos no PME 142 como: "a participação política; a gratuidade do ensino; a universalização da educação básica; a coordenação, o planejamento, a descentralização dos processos de decisão e execução, o fortalecimento das unidades escolares e dos conselhos de participação e controle social."

Alguns desses 42 PMEs elegem a apresentação de novos mecanismos para a gestão democrática, ou caminhos que favoreçam a gestão, configurando a segunda categoria de análise. Para traçar os possíveis novos mecanismos de gestão, investem, basicamente, em duas dimensões: a estruturação legal e o fortalecimento de organizações paritárias.

No que concerne à normatização/estruturação legal, os PMEs reforçam a necessidade da criação de leis que versem especificamente sobre gestão democrática ou eleição de diretores (muitas vezes percebidas como sinônimos), visualizadas através de estratégias que buscam "organizar estatuto ou normativa para a estruturação de todo o processo eleitoral ou escolhas de gestores nas Escolas Municipais" (PME 278).

Quanto ao fortalecimento de organizações paritárias, há o reforço para “a criação de organizações estudantis, bem como oferecer no mínimo semestralmente a formação para jovens lideranças das escolas" (PME 102); ou para a criação de espaços novos, como "a Casa dos Conselhos [...], que deverá abrigar os conselhos da educação, assegurando-lhes maior autonomia, condições físicas e financeiras para o funcionamento, com suporte técnico e operacional, inclusive para o deslocamento dos membros" (PME 331); ou ainda a "implementação, no prazo de dois anos, [...] o Conselho Municipal de Transporte Escolar" (PME 472).

Uma terceira categoria diz respeito à previsão de financiamento e controle específico para a gestão. Nessa categoria figuram, além de prescrições direcionadas especificamente ao financiamento, a proposição de conselhos e órgãos de fiscalização. 
Em relação ao financiamento, há especificações sobre verbas destinadas a conselhos, como "incluir na LDO e na LOA recursos financeiros para capacitação dos Conselheiros Municipais, bem como alimentação e transporte e disponibilizar espaço físico adequado para as reuniões mensais dos Conselhos Municipais" (PME 328), ou ainda "apoiar e disponibilizar recursos e ações para a constituição do Conselho Paritário de Transporte Escolar e criar Lei Municipal que normatize o Transporte Escolar" (PME 177).

Também há a previsão de participação específica de órgãos de controle na elaboração do orçamento público, como na estratégia de "manter a participação dos Conselhos da Secretaria Municipal de Educação na elaboração das Leis Orçamentárias (PPA, LDO e LOA), assim como audiência pública para aprovação das mesmas" (PME 437), ou no controle dos recursos aplicados, como na estratégia que indica a apresentação periódica "aos conselhos responsáveis relatórios de despesas com educação, com respectivas notas e fontes orçamentárias” (PME 155).

Tais ações convergem para a ideia que mecanismos de financiamento e controle público são dimensões relacionais à gestão democrática, na qual é preciso "fortalecer os mecanismos de transparência na aplicação e prestação pública de contas dos recursos de 100\% das unidades gestoras, na forma da lei, assegurados os princípios da gestão democrática e participativa" (PME 406).

A quarta categoria identificada diz respeito a ações tópicas vinculadas à gestão, informando uma variedade de ações com possíveis condições, de acordo com o legislador, para fomentar a democracia. Entre tais ações figuram, com primazia, o investimento na formação discente através de fóruns específicos, tais como "projetos comunitários como o Projeto Vereador Mirim" (PME 159), ou ainda o fórum municipal de juventudes, com assento no "CME e nas demais instâncias de discussão dos serviços oferecidos para a infância e a adolescência" (PME 424).

Porém, o movimento associado de forma direta a questões tópicas de gestão foi a avaliação, seja de uma modalidade específica, como a previsão de "desenvolver indicadores específicos de avaliação da qualidade da Educação Especial, bem como da qualidade da Educação Bilíngue para surdos, na perspectiva da gestão democrática" (PME 399); quanto à avaliação do próprio desenvolvimento da gestão democrática, em que é preciso "assegurar, durante a vigência do PME, condições para a efetivação da gestão democrática da educação, considerando avaliações anuais de desempenho perante a comunidade escolar" (PME 267); ou ainda "garantir o processo político através do qual as 
pessoas na escola discutem, deliberam e planejam, solucionam problemas e os encaminham, acompanham, controlam e avaliam o conjunto das ações voltadas ao desenvolvimento da própria escola" (PME 62).

As referências sobre a vinculação entre gestão democrática e aprendizagem (ou atividade-fim do processo de educação escolar) são bastante tímidas, dando a entender certo descolamento dos conceitos. Poucos excertos procuram avalizar “condições para a efetivação da gestão democrática, na educação básica que evidencie o compromisso com o acesso, a permanência e o êxito na aprendizagem do estudante do Sistema Municipal de Ensino" (PME 276).

Da mesma forma, o currículo figura como um possível instrumento de gestão democrática, no momento em que há a orientação para a "revisão e adequação dos currículos escolares por parte da mantenedora, conjuntamente com a participação do Conselho Escolar de cada unidade escolar, no âmbito de suas responsabilidades, tendo a legislação vigente como base, no prazo de 1 (um) ano a contar da aprovação do PME” (PME 303).

O que chama a atenção nessas ações é o seu distanciamento em relação ao posicionamento ideológico do PNE. Uma leitura superficial da meta 19 da lei $\mathrm{n}^{\circ}$ 13.005/2014 permite inferir que a participação popular é um elemento associativo e secundário para o PNE. Nos planos municipais examinados, ao contrário, a maioria das situações eleva a participação popular a uma condição de protagonista nas ações vinculadas à gestão democrática.

As ações relacionadas ao processo eleitoral/provimento de diretores/gestores de escolas públicas figuram como a quinta categoria identificada no texto dos PMEs, quando especificam ou detalham com mais nitidez a gestão democrática.

Nessa direção, há estratégias genéricas que carecerão de detalhamentos futuros, como na previsão da "consolidação e aperfeiçoamento do processo de escolha democrática dos diretores das escolas públicas” (PME 134). Mas há também estratégias com foco na perspectiva da formação para a gestão ou o pleito, como na oferta da "capacitação [para] a comunidade escolar, anteriormente à implantação da eleição de direção para prepará-los para a concretização da gestão democrática nas unidades escolares" (PME 128), ou ainda na exigência de "formação em nível de especialização lato sensu em Gestão Escolar ou áreas afins para ocupação de cargos de direção e coordenação das escolas municipais” (PME 123).

Um terceiro tipo de estratégia encontrada na categoria em análise, é a estratégia que indexa a gestão democrática a planos de carreira e regulamentação específica, como no ato de assegurar "a gestão democrática, garantindo no plano de carreira consulta popular para diretores, de forma a garantir o pleito 
democrático, no município" (PME 491), ou ainda "regulamentar legislação específica para eleição de diretores(as) de escola a cargo do Conselho Municipal de Educação, estabelecendo critérios aos profissionais em efetivo exercício no magistério público municipal, interessados em inscrever chapas para concorrer ao referido cargo" (PME 12).

Apesar do caráter legalista de estratégias como as mencionadas, compreende-se que o legislador busca garantir a gestão democrática em práticas sociais, mas, sobretudo, em determinações legais (mais difíceis de serem burladas ou coagidas).

Por fim, o excerto a seguir subverte a lógica do PNE, colocando o foco em critérios técnicos e a participação da comunidade escolar antes mesmo da eventual eleição/nomeação. Diz textualmente que o território municipal signatário do PME irá:

Priorizar o repasse de transferências voluntárias na área da educação para o Estado e o Município, desde que tenham aprovada lei específica, prevendo a observância de critérios técnicos sem meritocracia e sem desempenho e a processos que garantam a participação da comunidade escolar preliminares ao processo eleitoral e à nomeação comissionada de diretores escolares. (PME 253).

Nessa quinta categoria, é possível perceber, ainda, o esforço demandado pela inclusão das diferentes etapas da educação básica nos processos de gestão democrática estão expressos em excertos, como: “criar uma lei de gestão democrática para as escolas de educação infantil" (PME 224) ou, ainda, "instituir até 2018 a Lei Municipal que define critérios de seleção e participação na eleição de diretores de escolas e CEIs" (PME 108).

A sexta categoria problematiza a previsão de ações específicas para capacitação/formação de recursos humanos voltados à gestão, com duas dimensões perceptíveis: a seleção de recursos humanos específicos para trabalhar com a gestão democrática e a formação do pessoal em serviço.

No que concerne a recursos humanos específicos para o desenvolvimento de ações de gestão, cabe destaque a dois excertos: a previsão de "pessoal administrativo, pedagógico e operacional, capacitando-os para colaborar com uma gestão eficiente e democrática, favorecendo um atendimento de qualidade a toda comunidade escolar" (PME 78), ou ainda a efetivação "em até três anos a contar da vigência deste PME, o cargo de Agente de Educação e Cidadania como apoio da democratização da gestão, garantindo um elo permanente entre a escola e a família" (PME 347). 
No tocante à formação específica, chama a atenção a demanda pelo regime de colaboração para o desenvolvimento "em colaboração com a União, Estado, Municípios e parcerias público-privadas de programas de formação de diretores e gestores escolares" (PME 99); ou a previsão da oferta "através de parcerias e/ou programas próprios, formação de diretores e gestores escolares com vistas à qualidade da gestão democrática" (PME 204); ou mesmo a instituição de "uma política municipal de formação de gestores educacionais que contemple conselhos municipais, diretores, coordenadores e equipe técnica da Smed" (PME 127).

Mas há também uma estratégia que chama atenção por tocar em um ponto-chave das administrações quadrienais: a constante troca de pessoal responsável pela mantenedora, o que gera eventual descontinuidade de projetos e ações. Menciona a estratégia ser necessário garantir:

Dois docentes de provimento efetivo, com formação superior e pós-graduação em curso na área da educação, deverão compor o quadro de servidores da Secretaria de Educação de forma permanente para que a gestão democrática, administrativa e pedagógica não perca sua continuidade nas trocas sucessivas de governos. (PME 439).

Após a leitura dos 42 PMEs, que apresentam conteúdos diversos do PNE e/ou PEE, reforça-se a concepção da gestão como processo, como uma dimensão prática e discursiva em permanente construção. A gestão democrática é, pois, em sua gênese, uma categoria política, epistêmica e metodológica irredutível a precárias dimensões. De tal modo, ela é constituída pela multidimensionalidade e historicidade, não sendo possível compreendê-la de forma unilateral ou estanque.

\section{GESTÃO DEMOCRÁTICA: INDICADORES PRÁTICOS}

Desde a Constituição de 1988 convivemos com debates, pesquisas e pautas que consideram como ponto em comum a expressão "gestão democrática". De acordo com Vieira e Vidal (2019, p. 12): “A expressão integrava as palavras de ordem do movimento de educadores em tempos então conhecidos como de 'abertura' política, os quais assinalaram a transição da ditadura para a democracia." Tal expressão foi conquistada no corpo do dispositivo constitucional, através de pressões e mobilizações em torno da consolidação da (re)democratização, em que "os movimentos organizados de educadores, desde muito antes da Assembleia Nacional Constituinte (1987), expressavam demandas pela gestão democrática.” (p. 14). 
Entretanto, contextos alteram-se no desenrolar da história, instando o pesquisador a constantes atualizações. No vértice da condição histórica da expressão, há elementos que indicam a necessária construção do conceito e retomada permanente de práticas democráticas em todos os âmbitos, mormente na educação, uma vez que:

A força do poder, o influxo neoliberal e as reformas economicistas, de um lado, e as lutas travadas a partir da participação popular, de outro, estampam que, por aqui, a democracia segue sendo um campo de profundas contradições, tencionados referenciais de dignidade humana e do exercício da cidadania, como a qualidade da participação política dos atores sociais. (RIBEIRO; NARDI, 2018, p. 9).

Parece lícito supor, portanto, que a efetiva constituição e a necessária legitimação da gestão democrática ocorrem a partir das práticas sociais efetivas que se associam ao princípio, sendo, portanto, necessário indicar, confessadamente, o que materializa a gestão democrática, buscando evidências cotidianas dessa prática social e dos mecanismos estabelecidos e acionados por ela. É na prática social que se legitima a gestão democrática, dado que:

[...] gestão é administração, é tomada de decisão, é organização, é direção. Relaciona-se com a atividade de impulsionar uma organização a atingir seus objetivos, cumprir sua função, desempenhar seu papel. Constitui-se de princípios e práticas decorrentes que afirmam ou desafirmam os princípios que a geram. Estes princípios, entretanto não são intrínsecos à gestão como a concebia a administração clássica, mas são princípios sociais, visto que a gestão da educação se destina à promoção humana. (FERREIRA, 2008, p. 306).

O desenho do que efetivamente materializa a gestão democrática, ou os seus lugares e práticas, está presente em diversas legislações, compreendendo as normativas legais como uma marca indelével - por histórica e contextual - das intenções, arranjos e arenas em disputa de um determinado contexto sociopolítico e educacional.

Há construções materiais nas escolas e redes de ensino que já estão “prontas” para práticas de gestão democrática. Exemplarmente, é lícito interpretar que o projeto político-pedagógico da escola é um lugar de gestão democrática, assim como os conselhos escolares ou equivalentes, que seriam exemplos de instâncias desse tipo de gestão. Tem-se, neste caso, os conselhos e fóruns de educação; CE; grêmio estudantil; associações de pais; associações sindicais, entre outros. Também são exemplos de práticas de gestão democrática todo tipo 
de eleição em unidades educativas, da eleição de diretores à eleição do grêmio estudantil; reuniões pedagógicas, conselhos de classe, assembleias deliberativas e/ ou de prestação de contas, etc.

Mas quais os consensos em torno das práticas imprescindíveis para a materialização da gestão democrática? Parece adequada a compreensão de que a prática material desse tipo de gestão implica em: autonomia, livre organização dos segmentos, grupos engajados e ampliados, participação qualificada em pautas decisórias, transparência, e descentralização nas/das decisões.

Para que a gestão democrática receba contornos práticos e mensuráveis, parece pertinente que o princípio se firme, de acordo com Dourado e Amaral (2011, p. 303), “como espaço de deliberação coletiva (estudantes, funcionários, professores, pais ou responsáveis)" e que o princípio da democracia seja consolidado "como base para a melhoria da qualidade da educação e aprimoramento das políticas educacionais, enquanto políticas de Estado articuladas com as diretrizes nacionais para todos os níveis e modalidades de educação/ensino.” (p. 303).

O entendimento do princípio de gestão democrática, ou de todos os lugares e práticas nele implicados, bem como o alcance das ações de gestão democrática não são padronizados ou consensuais. Os textos legais e a bibliografia acerca do tema podem apresentar diferenças significativas em relação aos meandros do conceito, aos mecanismos previstos e o alcance e amplitude das ações estipuladas, principalmente em razão da grande "variedade nas políticas e na legislação dos sistemas de ensino, que regulamentam a matéria, [o que] resulta em uma diversidade de experiências no âmbito da democratização do ensino." (OLIVEIRA; CAMARGO; GOUVEIA; CRUZ, 2009, p. 150), justificando a necessidade de constante monitoramento e assegurando ao tema uma fonte quase inesgotável de possibilidades de pesquisa.

São, portanto, as práticas cotidianas que dão forma à gestão supostamente democrática em cada rede, sistema ou unidade educativa, pois "o saber sobre a política e a democracia se constrói, em última instância, na própria prática social" (PARO, 2001, p. 39). Nessa perspectiva, parece adequado compreender que a gestão democrática "somente tem força quando penetra e transforma as relações sociais concretas. E isso demanda colocar a democracia em ação, vale dizer, para além do princípio; implica considerá-la como procedimento" (SOUZA, 2019, p. 273-274). É no cotidiano cambiante e contextual de escolas e redes de ensino que ocorre, ou não, a materialização do princípio em questão.

Apesar da discussão sobre o princípio da gestão democrática do ensino público ainda estar bastante calcada na retórica e na retomada constante do conceito que envolve o princípio, é possível descrever concretamente indicativos 
para as práticas materializáveis de gestão democrática, principalmente quando examinamos legislações locais que têm o condão de proximidade e detalhamento em relação a tais práticas.

De tal modo, a gestão democrática pode ser caracterizada como um mecanismo que se materializa a partir de três dimensões: a) a presença, ampliação e qualificação de fóruns decisórios (que implica na livre organização dos sujeitos e segmentos envolvidos no processo educativo, garantindo sua participação efetiva); b) o respeito pela comunidade escolar, seus sujeitos e processos (autonomia, descentralização e valorização dos profissionais da educação); c) o controle social (transparência e eficiência em relação às ações e aos recursos).

\section{CONSIDERAÇÕES FINAIS}

Acompanhando a letra legal parece lícito supor que o que constitui e legitima a gestão democrática são as práticas sociais efetivas, sendo, portanto, necessário tracejar, claramente, o que materializa esse tipo de gestão, buscando evidências cotidianas dessas práticas sociais e dos mecanismos nelas estabelecidos e acionados. Assim, a legislação local - notadamente os PMEs, no caso em estudo - é constituída de indicadores das possibilidades de tal materialidade.

No estudo desenvolvido, foi possível aferir que, para materializar a gestão democrática, os planos municipais sul-rio-grandenses tendem a alinhar-se prioritariamente ao descrito no PNE. Algumas hipóteses são arguidas para esse propósito, como o fato do plano nacional ter sido elaborado anteriormente ao plano estadual, e assim muitos municípios apenas basearam-se no plano nacional, não levando em consideração as contribuições do plano estadual (muitos planos municipais foram elaborados no mesmo período da elaboração do plano estadual, e alguns municípios aprovaram seus planos municipais antes mesmo do plano estadual). Mesmo assim, 42 PMEs apresentaram conteúdos diferentes - mais detalhistas, explicativos ou regionalizados - em relação ao PNE, o que permitiu adensar noções e perspectivas de gestão democrática.

Por fim, e com base na análise dos PMEs, é possível indicar que a gestão democrática do ensino público pode ser caracterizada como um mecanismo que se materializa a partir de três dimensões: a) a presença, ampliação e qualificação de fóruns decisórios (que implica na livre organização dos sujeitos e segmentos envolvidos no processo educativo, garantindo sua participação efetiva); b) o respeito pela comunidade escolar, seus sujeitos e processos (autonomia, descentralização e valorização dos profissionais da educação); c) o controle social (transparência e eficiência em relação às ações e aos recursos). Também com base nos referidos PMEs, desenham-se minimamente indicadores que expressam a 
dimensão prática e normativa da gestão democrática nos municípios gaúchos, instituídos frente à polissemia do significante "democracia" e da imprecisão da legislação nacional.

\section{REFERÊNCIAS}

BARDIN, Laurence. Análise de conteúdo. Trad. Luiz Antero Reto e Augusto Pinheiro. Lisboa: Edições 70, 2007.

BRASIL. Presidência da República. Casa Civil. Subchefia para Assuntos Jurídicos. Constituição da República Federativa do Brasil, 1988. Disponível em: http:/ / www.planalto.gov.br/ccivil_03/constituicao/constituicao.htm. Acesso em: 10 jun. 2019.

BRASIL. Presidência da República. Casa Civil. Subchefia para Assuntos Jurídicos. Lei $\mathbf{n}^{0}$ 9.394. Estabelece as diretrizes e bases da educação nacional. Brasilia: Casa Civil, 1996. Disponível em: http://www.planalto.gov.br/CCIVIL_03/leis/L9394. htm. Acesso em: 10 jul. 2019.

BRASIL. Presidência da República. Casa Civil. Subchefia para Assuntos Jurídicos. Lei $\mathbf{n}^{\mathbf{o}}$ 13.005, de 25 de junho de 2014. Aprova o Plano Nacional de Educação - PNE e dá outras providências. Disponível em: http://www.planalto.gov.br/ ccivil_03/_Ato2011-2014/2014/Lei/L13005.htm. Acesso em: 10 jul. 2019.

DOURADO, Luiz F.; AMARAL, Nelson C. Financiamento e gestão da educação e o PNE 2011-2020: avaliação e perspectivas. In: DOURADO, Luiz F. (Org.). Plano Nacional de Educação (2011-2020): avaliação e perspectivas. Goiânia: Editora UFG; Belo Horizonte: Autêntica, 2011, p. 285-315.

DOURADO, Luiz Fernando. A escolha de dirigentes escolares: políticas e gestão da educação no Brasil. In: FERREIRA, Naura Syria Carapeto (Org.). Gestão democrática da educação: atuais tendências, novos desafios. 8. ed. São Paulo: Cortez, 2013.

FERREIRA, Naura S. C. Gestão democrática da educação: atuais tendências, novos desafios. São Paulo: Cortez, 2008. 
GRACINDO, Regina Vinhaes. Gestão democrática nos sistemas e na escola. Curso técnico de formação para os funcionários da educação. Brasília: Universidade de Brasília, 2007.

MARQUES, Luciana Rosa. A formação de uma cultura democrática na gestão da escola pública: analisando o discurso dos conselheiros escolares. Educação \& Sociedade, Campinas, v. 33, n. 121, p. 1175-1194, dez. 2012.

OLIVEIRA, João Ferreira de; CAMARGO, Rubens Barbosa de; GOUVEIA, Andréa Barbosa; CRUZ, Rosana Evangelista da. Gestão democrática e qualidade de ensino em escolas de educação básica. Revista Retratos da Escola, Brasília, v. 3, n. 4, p. 149-162, jan./jun. 2009.

PARO, Vitor Henrique. Escritos sobre educação. São Paulo: Xamã, 2001.

PARO, Vitor Henrique. Gestão democrática da escola pública. 4. ed. rev. atual. São Paulo: Cortez, 2016.

PASSADOR, Cláudia Souza; SALVETTI, Thales Silveira. Gestão escolar democrática e estudos organizacionais críticos: convergências teóricas. Educação e Sociedade, v. 34, n. 23, p. 477-492, jun. 2013.

RIBEIRO, Raimunda Maria da Cunha; NARDI, Elton Luiz. Bases normativas e condições político-institucionais da gestão democrática em sistemas municipais de ensino do estado do Piaú. Ensaio: Avaliação e Políticas Públicas em Educação. Rio de Janeiro, v. 26, n. 98, p. 7-31, mar. 2018.

RIO GRANDE DO SUL. Lei $\mathbf{n}^{\mathbf{0}} \mathbf{1 4 . 7 0 5 / 1 5}$. Institui o Plano Estadual de Educação - PEE. Disponível em: http://simec.mec.gov.br/sase/sase_mapas. php?uf=RS\&tipoinfo=1. Acesso em: 12 mai. 2019.

SOUZA, Ângelo Ricardo de. As condições de democratização da gestão da escola pública brasileira. Ensaio: Avaliação e Políticas Públicas em Educação. Rio de Janeiro, v. 27, n. 103, p. 271-290, jun. 2019.

VIEIRA, Sofia Lerche; VIDAL, Eloísa Maia. Liderança e gestão democrática na educação pública brasileira. Revista Eletrônica de Educação, v. 13, n. 1, p. 11 25, jan./abr. 2019. 


\section{Rosimar Serena Siqueira Esquinsani}

Doutora em Educação (Unisinos). Pesquisadora Pq/CNPq 2. Professora e pesquisadora do Programa de Pós-Graduação em Educação da Universidade de Passo Fundo (UPF). E-mail: resquinsani@gmail.com

\section{Jarbas Dametto}

Doutor em Educação (UPF). E-mail: dametto@gmail.com

\section{Munir José Lauer}

Doutorando em Educação (UPF). Professor de Educação Física da rede estadual de ensino, em Pontão/RS. E-mail: dametto@gmail.com

Recebido em 10 setembro de 2019. Aprovado em 16 março de 2020. 